\title{
Video assisted resections. Increasing access to minimally invasive liver surgery?
}

\author{
Ressecções videoassistidas. Ampliação do acesso à cirurgia hepática \\ minimamente invasiva?
}

Fabricio Ferreira Coelho, TCbC-SP1; Marcos Vinícius PerinI 1,2; Jaime Arthur Pirola Kruger 1,2; Renato Micelli lupinacci 1,3; Fábio Ferrari MakdissI²; Luiz Augusto Carneiro D’Albuquerque, TCBC-SP4; Ivan Cecconello, TCBC-SP5; Paulo Herman, TCBC-SP6

A B S T R A C T

\begin{abstract}
Objective: To evaluate perioperative outcomes, safety and feasibility of video-assisted resection for primary and secondary liver lesions. Methods: From a prospective database, we analyzed the perioperative results (up to 90 days) of 25 consecutive patients undergoing video-assisted resections in the period between June 2007 and June 2013. Results: The mean age was 53.4 years (23$73)$ and $16(64 \%)$ patients were female. Of the total, $84 \%$ were suffering from malignant diseases. We performed 33 resections (1 to 4 nodules per patient). The procedures performed were non-anatomical resections $(n=26)$, segmentectomy $(n=1), 2 / 3$ bisegmentectomy $(n=1), 6 / 7$ bisegmentectomy $(n=1)$, left hepatectomy $(n=2)$ and right hepatectomy $(n=2)$. The procedures contemplated postero-superior segments in $66.7 \%$, requiring multiple or larger resections. The average operating time was 226 minutes (80-420), and anesthesia time, 360 minutes (200-630). The average size of resected nodes was $3.2 \mathrm{~cm}(0.8$ to 10$)$ and the surgical margins were free in all the analyzed specimens. Eight percent of patients needed blood transfusion and no case was converted to open surgery. The length of stay was 6.5 days (3-16). Postoperative complications occurred in $20 \%$ of patients, with no perioperative mortality. Conclusion: The video-assisted liver resection is feasible and safe and should be part of the liver surgeon armamentarium for resection of primary and secondary liver lesions.
\end{abstract}

Key words: Liver Neoplasms. Hepatectomy. Laparoscopy. Video-Assisted Surgery.

\section{INTRODUCTION}

$\mathrm{H}$ epatic resection is one of the last frontiers transposed by minimally invasive surgery. Initial suspicions that had to be overcome for its development were the theoretical risk of air embolism, of uncontrollable intraoperative bleeding, uncertainties about getting adequate surgical margins, risk of tumor dissemination in the cases of malignancies and the need for large incorporation of technology (energy sources, vascular staplers, laparoscopic transducers to perform the intraoperative ultrasound and specific retractors to liver mobilization) $)^{1,2}$. In addition, the method's learning curve is steep, requiring surgeons with experience in liver surgery and advanced laparoscopic surgery training ${ }^{2-4}$.

Driven by good initial results, different series have shown that laparoscopic liver resections (LLR) are feasible, safe and provide benefits over the conventional approach. Among the advantages of LLR are less bleeding, lower incidence of perioperative complications, less postoperative pain, shorter hospital stay and lower incisional hernias rates $^{4,5}$.

The best candidates for the method are those with lesions in the antero-lateral liver segments (segments $2,3,4 b, 5$ and 6), also referred to as "laparoscopic segments" $1,5,6$. Currently, LLR in these segments, and the left side sectionectomy (bisegmentectomy 23 ), have been considered as the gold standard in centers specialized ${ }^{7}$. Challenges to laparoscopy are still the resection of multiple and bilateral lesions, nodules in the superior, posterior or central locations (segments 1, 4a, 7 and 8) and major hepatectomy ( $\mathrm{e}^{\prime \prime}$ three segments) ${ }^{1,2,5,6}$. However, with increasing experience with the method, the advent of new technologies and the development of alternative modalities within the minimally invasive liver surgery (MILS), the technical difficulties inherent to these resections could be overcome, enabling the successful realization of larger LLR, such as the left and right hepatectomy or even trisectionectomy ${ }^{8}$. More recently, LLR has been also applied for removing living donor liver grafts 9 .

\footnotetext{
1. Serviço de Cirurgia do Fígado e Hipertensão Portal do HCFMUSP, São Paulo, Brasil; 2. Instituto do Câncer do Estado de São Paulo (ICESP), São Paulo, Brasil; 3. Assistant Spécialiste, Service de Chirurgie Générale, Viscérale et Endocrinienne; Hôpital Pitié Salpetrière, Paris, France; 4. Disciplina de Transplantes de Órgãos do Aparelho Digestivo, FMUSP, São Paulo, Brasil; 5. Departamento de Gastroenterologia da FMUSP, São Paulo, Brasil; 6. Disciplina de Cirurgia do Aparelho Digestivo, FMUSP, São Paulo, Brasil.
} 
The modalities most commonly employed within the are purely (or fully) laparoscopic operation, the one with hand assistance and the video-assisted operation (hybrid). The purely laparoscopic is preferable in most services; in this mode the whole procedure is performed laparoscopically and an incision is performed at the end of the procedure for withdrawal of the specimen ${ }^{10,11}$.

Hand-assisted and video-assisted resections emerged in order to overcome some of the limitations of the totally laparoscopic approach and thus broaden MILS access and indications $\mathbf{s}^{1,10,11}$. These modalities allow handling closer to conventional hepatectomy and return the tactile sensation partially lost in laparoscopy, facilitating palpation and lesions identification, and allows the compression of the parenchyma during liver transection, providing greater safety ${ }^{1,12,13}$.

The hand-assisted approach has been used for resection of lesions located in the liver posterior-superior segments and major hepatectomy9,12,14. The major disadvantages of the method are fatigue by a non ergonomic position in prolonged operations, loss of gas through the hand portal and the high cost, since the hand insertion device device does not obviate the need for energy sources and vascular staplers for section of the hepatic parenchyma ${ }^{1,14}$.

Video-assisted or hybrid liver surgery, on its turn, is not widely used, but has potential that can spread its use. In this modality, the procedure is started via total laparoscopy or hand-assisted, with the performance of the complete liver mobilization; after that, a programmed minilaparotomy is carried, with section of the parenchyma by conventional means ${ }^{10,11,14}$. This mode has some of the advantages presented by the hand-assisted resection, the possibility of using the tactile perception for identification of deep lesions and aid in parenchymal section. The approach by the auxiliary incision allows maneuvers similar to conventional surgery such as liver compression and manual (or clamp) control of the vascular pedicle. The closeness with the conventional procedure can reduce the learning curve and the direct costs of the operation ${ }^{13,15}$.

The purpose of this paper is to present the results and evaluate safety and feasibility of video-assisted resection for primary and secondary liver injuries.

\section{METHODS}

From June 2007 to June 2013155 LLR were held in the Sevice of Liver Surgery and Portal Hypertension of the Hospital das Clínicas da Faculdade de Medicina da Universidade de São Paulo (HCFMUSP). Of these we studied 25 consecutive patients undergoing video-assisted liver resection from a prospective database. The study was approved by the Ethics in Research Committee of the institution under number 14260.
We defined hybrid resection as the procedure initiated totally laparoscopically or hand-assisted for mobilization liver (whether with dissection of the vascular pedicles and hepatic veins or not). After this, through elective minilaparotomy, dissection of the pedicles and hepatic veins was carried out (if not previously done) and the section of the parenchyma. Cases converted by intraoperative complications were excluded.

We included patients with primary and secondary liver lesions with liver resection indication according to their etiology (Table 1). Patients with hepatic adenomas underwent resection if symptomatic or if with lesions larger than $5 \mathrm{~cm}$. Patients with liver metastases of colorectal cancer and other types of cancer were operated within a context of control of the primary tumor and appropriate chemotherapy. Patients with liver cirrhosis and hepatocellular carcinoma (HCC) were candidates for surgery with preserved liver function (Child-Pugh A and Model for End-satge Liver disease [MELD] <10) and lesions considered resectable (preservation of at least $40-50 \%$ of liver parenchyma). Patients with liver cirrhosis and portal hypertension had selective indication, being considered eligible for surgery those with fine caliber esophageal varices and platelets $>100,000 / \mathrm{ml}$.

The indication for surgical treatment, as well as the access rout, was made after discussion in a multidisciplinary meeting. The video-assisted mode was considered in patients that anticipated preoperatively technical difficulties arising from the location, size or multinodularity, in particular when requiring major resections and resection of postero-lateral superior segments (1, 4a, 7 and 8).

We studied the following preoperative characteristics: age, gender, preoperative diagnosis, size and location of the lesions, previous surgeries, in addition to Child-Pugh and MELD scores in cirrhotic patients. Regarding the intra-operative period, the information of interest were: type of procedure, duration of surgery and anesthesia, need for blood transfusion, as well as intraoperative complications and the need for conversion.

Table 1 - Indications of the video-assisted liver resections.

\begin{tabular}{lc}
\hline Indication & $\mathbf{n}$ \\
\hline CRCHM & 11 \\
HCC & 8 \\
Hepatocellular adenoma & 4 \\
Anal canal SCC metastasis & 1 \\
Metastatic neuroendocrine tumor & 1 \\
Total & 25 \\
\hline
\end{tabular}

Source: Medical records, Service of Liver Surgery and Portal Hypertension (HCFMUSP-2007/2013).

CRCHM: liver metastasis of colorectal cancer, HCC: hepatocellular carcinoma, SCC: squamous cell carcinoma. 
In the postoperative period we studied the length of stay in ICU and hospital, clinical and surgical complications and early mortality (up to 90 days after the procedure). Complications were stratified according to the Dindo-Clavien classification ${ }^{16}$.

\section{Operative Technique}

The surgical technique was standardized, all patients were placed in Lloyd-Davis position with the surgeon standing between the patient's legs. For the right resections we placed a cushion under the right shoulder blade and an arc to accommodate the right upper limb, in addition to the use of the left lateral position $\left(45^{\circ}\right)$ to facilitate the exposure of the posterior right hepatic sector. For the left resections we used only a slight inclination. The pneumoperitoneum was performed by open technique, maintaining the intra-abdominal pressure between 12 and $14 \mathrm{mmHg}$. Central venous pressure was kept below $5 \mathrm{mmHg}$ to minimize the risk of bleeding during the section of the hepatic parenchyma.

In right hepatectomies or resections of segments of the right hepatic lobe, we used four or five portals, as depicted in Figure 1 A. We instilled the pneumoperitoneum in the periumbilical region and placed a $10 \mathrm{~mm}$ trocar for introduction of a $30^{\circ}$ endoscope. Under direct vision we placed two working trocars in the right hypochondrium, 8 to $10 \mathrm{~cm}$ apart from each other (Figure $1 \mathrm{~A}$ ). One of the assistants used the $5 \mathrm{~mm}$ subxiphoid trocar to retraction of the right hepatic lobe. In some cases we used an additional portal on the right flank between the middle and anterior axillary line to approach the ligaments of the right lobe (Figure 1A). We began the procedure in totally laparoscopic approach with the release of the round and falciform ligaments. After this, we divided the right triangular and coronary ligaments, guaranteeing the full mobilization of the right lobe. Thus, even lesions in posterior segments could be shifted to the left and addressed by the auxiliary incision. One could also, depending on the type of procedure and surgeon's skill, perform the dissection of the vascular pedicle and right hepatic vein at this operative time. After this, we performed a minilaparotomy in the right upper quadrant, joining the working portals, or a $8-10 \mathrm{~cm}$ supraumbilical midline incision (Figure 1A). In the case of malignant disease or anatomical doubt, at this time we performed intraoperative ultrasound with a conventional transducer by the auxiliary incision. Finally, we completed the procedure by conventional surgery with dissection and ligation of the pedicle (where necessary) and the section of liver parenchyma (Figure 2). We did not use vascular stapling devices in any case.

For the resections of lesions located in the left hepatic lobe we used three or four trocars positioned as depicted in Figure 1B. We placed the endoscope in the periumbilical region, the surgeon's working trocars to the right and left upper quadrant, and an additional trocar in some cases in the subxiphoid region to aid in the presentation of the liver (Figure 1B). We released the left triangular ligament to the right until the left hepatic vein, which we did not routinely isolate and dissect. After total hepatic liberation, we made a $8-10 \mathrm{~cm}$ supraumbilical midline incision and finished the procedure conventionally.

We selectively used the Pringle and hemi-Pringle maneuvers, when necessary ${ }^{17}$. We removed the surgical specimen through the auxiliary incision with a protective bag. The drainage of the surgical bed was not routine; when indicated, we used a closed system chest tube.
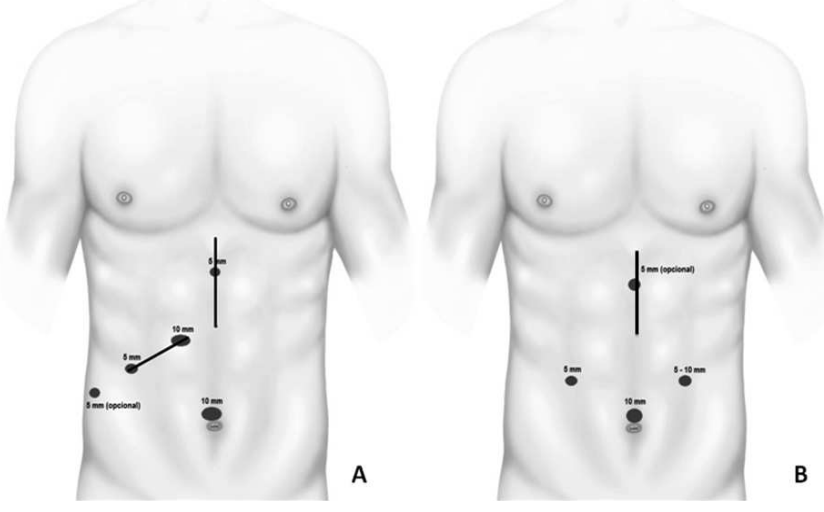

Figure 1 - A) placing of the portals for resections of lesions in the right lobe. Note the placement of working portals in the right hypochondrium in a more cranial position situated 8 to $10 \mathrm{~cm}$ from each other. The auxiliary incision can be made in the right upper quadrant joining the incisions of the working trocars or in the midline. B) Placing of portals for left lobe resections. The auxiliary incision is made in the midline, in a span of 8 to $10 \mathrm{~cm}$.

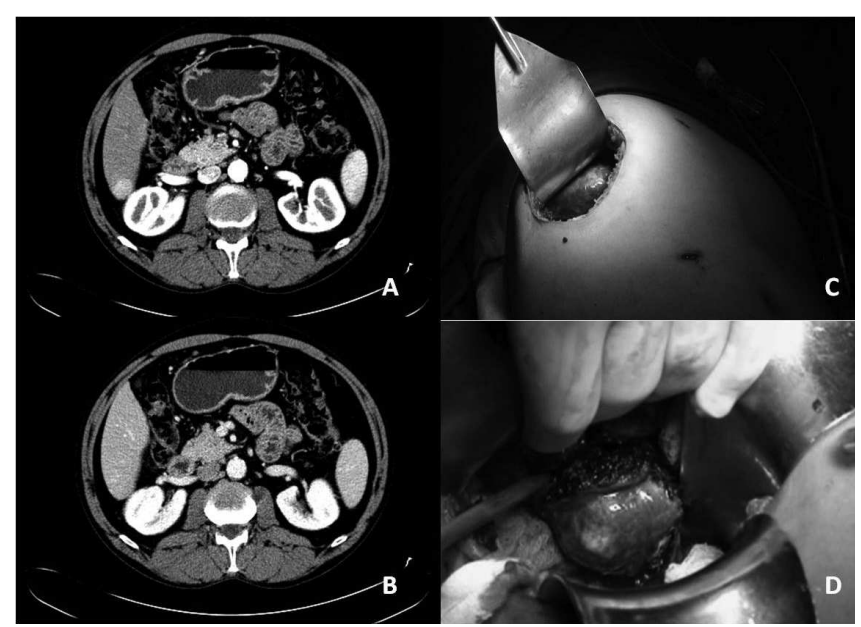

Figure 2 - $\quad$ Patient with chronic liver disease due to hepatitis $C$ virus and hepatocellular carcinoma (HCC). A and B) $2.5 \mathrm{~cm}$ lesion with wash-out in the segment 7. C) Auxiliary incision $(10 \mathrm{~cm})$ detail in the right upper quadrant. D) after the liver liberation, the right lobe can be shifted to the left, the lesion exteriorized through the incision, and the section of the hepatic parenchyma carried out with conventional techniques. 


\section{RESULTS}

From June 2007 to June 2013 we held 155 LLR 25 (16.1\%) being video-assisted hepatectomies. Of the 25 operated patients, 16 (64\%) were female. The average age was 53.4 years (range $23-73$ ). Thirteen patients (52\%) had previous abdominal surgery. Of the total, 21 (84\%) patients had primary or secondary malignancies of the liver. The eight patients with HCC were Child-Pugh A, with functional MELD ranging between 6 and 8, four (50\%) having signs of portal hypertension at endoscopy or tomography.

We performed a total of 33 resection, being extirpated from one to four nodules per patient ( 21 showed a single lesion, one patient two lesions, two patients three lesions and one patient four lesions). The average size of the resected nodules was $3.2 \mathrm{~cm}$ (0.8 to 10). Twenty lesions were located in the right lobe and 13 in the left lobe.

We initiated all procedures by the totally laparoscopic approach, with an auxiliary right subcostal incision in 14 cases and a median supraumbilical one in 11. The procedures performed are listed in Table 2 . Of the total, $22(66.7 \%)$ operated on postero-lateral superior segments, requiring multiple or larger resections. The mean duration of surgery was 226 minutes (80-420) and 360 minutes of anesthesia time (200-630). Surgical margins were free in all the analyzed specimens.

Two patients (8\%) had controlled bleeding during the procedure, requiring transfusion (1-2 units of packed red blood cells). No cases were converted. We referred 16 patients (64\%) to the ICU postoperatively, the average stay being 1.1 days ( 1 to 3 ). The mean hospital stay was 6.5 days (3-16).

Postoperative complications occurred in five patients (20\%) and are listed in Table 3. We managed most of the complications conservatively, with the need for elective repair of one incisional hernia and guided puncture and antibiotic therapy in one patient with a collection in the hepatic resection bed. There were no deaths related to the procedure.

\section{DISCUSSION}

Since the first report of performing peripheral LLR by Reich et al., The MILS underwent a major breakthrough ${ }^{18}$. Anatomical resections (bisegmentectomy 2-3) and later more complex resections were described as feasible and safe. The initial MILS experience developed primarily with a purely laparoscopic method, which is preferred by most services. A review of LLR literature published until 2008 showed that $75.1 \%$ of cases had been fully operated by laparoscopy, $16.5 \%$ by the hand-assisted approach and only $2.1 \%$ by the hybrid technique ${ }^{10}$. In our service, there is also a predilection for the pure laparoscopic mode when possible. During the study period $79.4 \%$ (136/155) of LLR were made by this technique, this being the method of choice for anterolateral resections and left lateral sectionectomy.

Despite the experience gain with the purely laparoscopy route, there are limitations inherent in the method that hinder its spread, among which we can mention the high direct cost for the need of large technological resources, the high level of technical proficiency required and the steep learning curve $e^{2,5,6}$. In one study addressing this question, Vigano et al. ${ }^{3}$ identified the need of 60 operated cases before reaching the maturity in terms of complications and results with the method. From a technical point of view, the main limitations are the difficulty of mobilizing and retracting the liver, the twodimensional view, difficult access to higher and higher liver segments, difficulty in dissecting the hepatic veins, as well as difficulty in performing vascular and biliary sutures. For this reason, the resection of lesions located in the posterior-superior liver segments, multiple bilobar resections and major hepatectomy, although achievable, are still challenging, being indicated in selected cases ${ }^{1,6,8}$.

In this context arose the video-assisted surgery, aiming to overcome some of the limitations of the totally laparoscopic mode, thus expanding access and enhancing LLR security $12,14,19$. The first hybrid resections were reported by Huscher et al. ${ }^{20}$, who applied the method for larger right resections. Although not widely used, video-assisted

Table 2 - Types of video-assisted procedures performed.

\begin{tabular}{lrr}
\hline Procedure & \multicolumn{2}{c}{$\mathrm{n}(\%)$} \\
\hline Non-anatomical resections & 26 & $(78.8 \%)$ \\
Segmentectomy & 1 & $(3 \%)$ \\
Bisegmentectomy $2-3$ & 1 & $(3 \%)$ \\
Bisegmentectomy 6-7 & 1 & $(3 \%)$ \\
Left hepatectomy & 2 & $(6.1 \%)$ \\
Right hepatectomy & 2 & $(6.1 \%)$ \\
Total & 33 & \\
\hline
\end{tabular}

Source: Medical records, Service of Liver Surgery and Portal Hypertension (HCFMUSP-2007/2013).

Table 3 - Frequency and classification of postoperative complications.

\begin{tabular}{lccc}
\hline Complication & \multicolumn{2}{c}{ n (\%) } & Classification * \\
\hline Incisional Hernia & 1 & $(4 \%)$ & dIIIB \\
Intra-abdominal fluid collection & 1 & $(4 \%)$ & IIIA \\
Hepatic Encephalopathy & 1 & $(4 \%)$ & II \\
lleus & 1 & $(4 \%)$ & 1 \\
Ascites & 1 & $(4 \%)$ & $\mathrm{I}$ \\
Total & 5 & $(20 \%)$ & - \\
\hline
\end{tabular}

Source: Medical records, Service of Liver Surgery and Portal Hypertension (HCFMUSP-2007/2013).

* Stratification according to the Dindo-Clavien Classification ${ }^{16}$ 
hepatectomy has potential benefits that can justify its spread. First, this technique can attach the benefits of laparoscopy for liver mobilization, without the need of large incisions to access the liver, with "security" of the conventional resection, particularly in times of increased risk, such as during parenchymal section ${ }^{13,15,19}$. By being closer to the conventional method, it requires less learning curve and can be used by surgeons with less experience in advanced laparoscopic surgery. For this reason, it's the choice (even for simple resections) on services which are starting their experience in MILS. The technical standardization and training obtained from the liver release can serve as a basis for conducting more complex, entirely laparoscopic resections ${ }^{14}$.

It is difficult for most centers to have all the necessary resources to fully carry out laparoscopic procedures. In this situation, the hybrid technique can also be an attractive option, since it enables the performance of LLR without the use of specific energy sources and vascular stapling to the section of the parenchyma and without the use of laparoscopic transducers to perform the intraoperative ultrasonography in malignant diseases, which considerably reduces the procedure's direct costs ${ }^{15,21}$.

The video-assisted approach can be used for any type of LLR; however, its best indication occurs when there is foreseen technical difficulty in locating or resecting a lesion, being an extremely useful option for those located in the segments of difficult laparoscopic access, for multiple resections and for major hepatectomy ${ }^{21,22}$. In this series, these conditions were present in $66.7 \%$ of the indications.

In a multicenter study of 210 major hepatectomies, Dagher et al. reported that only $43.3 \%$ of the procedures were performed by the totally laparoscopic technique ${ }^{23}$. In a recent publication, Nitta et al. showed that in Japanese centers $88.7 \%$ of major hepatectomies are carried out by the hybrid technique, versus only $7.5 \%$ for the pure laparoscopic technique and 3.8\% with hand assistance ${ }^{24}$. Consistent with these data, a systematic review comparing the modalities purely laparoscopic, hand-assisted and hybrid for larger resections showed that video-assisted technique has its greatest applicability in lesion resections in difficult places, patients predicted to pose technical difficulties (such as in patients with chronic liver disease and $\mathrm{HCC}$ ) and resections requiring delicate hilar dissection, such as living donors hepatectomy. In the latter subgroup a hybrid approach has wide applicability, being the preferred technique in many transplant centers, with superior results and complication rates similar to conventional hepatectomy ${ }^{25}$.

The hybrid mode may also be useful in cases of resection for malignant disease, which is currently the dominant indication in most series, as well as in ours $(84 \%)^{10,26}$. Intraoperative ultrasound is essential in these cases, because even with modern imaging methods it may change the surgical approach in as much as $25 \%$ of ca$\operatorname{ses}^{27}$. However, laparoscopic transducers are still difficult to access for most services. In addition, one of the great obstacles of laparoscopy is loss of tactile sensation, which can impair the finding of non-superficial lesions and thus hamper the achievement of adequate oncological margins ${ }^{19}$. With the hybrid approach these problems can be overcome; the Union between tactile palpation and ultrasound (performed with conventional equipment) may explain the high rate of free margins in our series.

Potential disadvantages of this method are inadequate exposure of the liver to manipulation by the auxiliary incisions and doubt regarding the possible loss of benefits of laparoscopy. One of the fundamental points in the video-assisted surgery is complete liver mobilization, thus it is essential that for lesions on the right side the triangular and coronary ligaments are fully released, as well as the round and falciform ligaments. Additionally, the positioning of the patient in sharp left lateral position is important, ensuring that even posterior lesions can be displayed and manipulated through small incisions in the anterior abdominal wall. In left resections the ligaments' release is usually enough to liver mobilization, a sharp decubitus not being generally necessary. The choice of the incision site is also important for technical success; we prefer a right subcostal incision for the access to lesions in the posterior region, however, there are authors who perform the procedure with a median incision with good results ${ }^{19,22}$. On the left or bilobar resections a median incision allows access to all segments, being the one of choice.

Regarding the results of hybrid resections, some authors have demonstrated its feasibility and safety ${ }^{28-30}$. We observed no intraoperative complications, transfusion being required in $8 \%$ of patients, similar to that reported by other authors $^{14,15,28-30}$. The conversion rate was zero, reaching $7 \%$ in the literature ${ }^{13,14,26,30}$. The frequency of $20 \%$ of postoperative complications found in this study is in agreement with other series, which report rates ranging from 5.7 to $24 \%^{13,14,21,26}$, noting that most resections performed were complex and complications were of low gravity, with no complications comprising organ dysfunction or readmission to the ICU.

Comparative studies show that the hybrid resections maintain the safety of conventional ones, with no increase in complications, causing less postoperative pain and shorter hospital stay ${ }^{15,31}$. Johnson et al. compared the results of conventional and hybrid surgery (125 conventional versus 88 hybrid) and found similar complication rates ( $10.5 \%$ conventional versus $6.8 \%$ hybrid, $p=0.59$ ) with a reduction in hospital stay in the video-assisted group ${ }^{31}$. Koffron et al. ${ }^{13,14}$ reported the maintenance of laparoscopy benefits with hybrid surgery, demonstrating that except for a higher surgical time, it displays results similar to other minimally invasive modalities, and better than the conventional on as for blood loss, transfusion requirements and complication rates ${ }^{14}$.

The good results, together with the security achieved with the method, caused the interest in its use to 
grow in recent years, especially in Asian centers 15,21,22,24. A recent survey in 124 Japanese centers showed that, currently, $32.7 \%$ of LLR are held by the hybrid technique ${ }^{26}$, higher than the number reported in our series (16.1\%) and denoting the growth potential of the method compared to the $2.1 \%$ initially reported ${ }^{11}$.

This study represents the largest Brazilian experience on the video-assisted liver resection and, despite its non-comparative character, attests the good results of the method, with low immediate mortality, high complete resection rate of injuries and low frequency of complications. We believe that the method may have great impact on the development of MILS and may be indicated at the beginning of experience in centers for training as an alternative technique for lesions in "non-laparoscopic segments" and in cases of technical difficulties, or even where there is no availability of some high-cost items such as staplers and transducers. However, more prospective and comparative studies are still needed to consolidate its real indications, advantages, and the best candidates to the method.

We can conclude from the above that the videoassisted liver resection is feasible and safe and should be part of the liver surgeon armamentarium for resection of primary and secondary liver lesions.

\section{Acknowledgements}

We thank the artist Marcos Retzer for his help with the illustrations of this work.

\title{
R E S U M O
}

\begin{abstract}
Objetivo: avaliar os resultados perioperatórios, segurança e exequibilidade das ressecções videoassistidas para lesões hepáticas primárias e secundárias. Métodos: a partir de um banco de dados prospectivo, foram analisados os resultados perioperatórios (até 90 dias) de 25 pacientes consecutivos submetidos à ressecções videoassistidas, no período entre junho de 2007 e junho de 2013. Resultados: a média de idade foi 53,4 anos (23 a 73 anos), sendo 16 (64\%) pacientes do sexo feminino. Do total, $84 \%$ eram portadores de patologias malignas. Foram realizadas 33 ressecções (1 a 4 nódulos por paciente). Os procedimentos realizados foram: ressecções não regradas $(n=26)$, segmentectomia $(n=1)$, bissegmentectomia $2 / 3(n=1)$, bissegmentectomia $6 / 7$ ( $n=1)$, hepatectomia esquerda ( $n=2)$, hepatectomia direita ( $n=2)$. Do total, 66,7\% dos procedimentos foram em segmentos póstero-superiores, necessitaram de resecções múltiplas ou ressecções maiores. O tempo médio de operação foi 226 minutos (80-420 min) e o tempo de anestesia de 360 minutos (200-630 min). O tamanho médio dos nódulos ressecados foi 3,2cm (0,8 a $10 \mathrm{~cm})$ e as margens cirúrgicas foram livres em todos os espécimes analisados. Foram transfundidos $8 \%$ dos pacientes e nenhum caso foi convertido. 0 tempo de internação foi 6,5 dias (3 a 16 dias). Complicações pós-operatórias ocorreram em 20\% dos pacientes, não havendo mortalidade perioperatória. Conclusão: a ressecção hepática videoassistida é exequível e segura, devendo fazer parte do armamentário do cirurgião de fígado para ressecções de lesões hepáticas primárias e secundárias.
\end{abstract}

Descritores: Neoplasias Hepáticas. Hepatectomia. Laparoscopia. Cirurgia Videoassistida.

\section{REFERENCES}

1. Viganò L, Tayar C, Laurent A, Cherqui D. Laparoscopic liver resection: a systematic review. J Hepatobiliary Pancret Surg. 2009;16(4):410-21

2. Herman P, Coelho FF, Lupinacci RM, Perini MV, Machado MAC, D'Albuquerque LAC, e al. Ressecções hepáticas por videolaparoscopia. ABCD, arq bras cir dig. 2009;22(4):226-32.

3. Vigano L, Laurent A, Tayar C, Tomatis M, Ponti A, Cherqui D. The learning curve in laparoscopic liver resection: improved feasibility and reproducibility. Ann Surg. 2009;250(5):772-82.

4. Mirnezami R, Mirnezami AH, Chandrakumaran K, Abu Hilal M, Pearce NW, Primrose JN, et al. Short- and long-term outcomes after laparoscopic and open hepatic resection: systematic review and meta-analysis. HPB. 2011;13(5):295-308.

5. Rao A, Rao G, Ahmed I. Laparoscopic or open liver resection? Let systematic review decide it. Am J Surg. 2012;204(2):222-31.

6. Nguyen KT, Geller DA. Laparoscopic liver resection--current update Surg Clin North Am. 2010;90(4):749-60.

7. Rao A, Rao G, Ahmed I. Laparoscopic left lateral liver resection should be a standard operation. Surg Endosc. 2011;25(5):160310.

8. Lin NC, Nitta H, Wakabayashi G. Laparoscopic major hepatectomy: a systematic literature review and comparison of 3 techniques. Ann Surg. 2013;257(2):205-13
9. Koffron AJ, Kung R, Baker T, Fryer J, Clark L, Abecassis M Laparoscopic-assisted right lobe donor hepatectomy. Am J Transplant. 2006;6(10):2522-5

10. Nguyen KT, Gamblin TC, Geller DA. World review of laparoscopic liver resection-2,804 patients. Ann Surg. 2009:250(5):831-41.

11. Buell JF, Cherqui D, Geller DA, O'Rourke N, lannitti D, Dagher I, et al. The international position on laparoscopic liver surgery: The Louisville Statement, 2008. Ann Surg. 2009;250(5):825-30.

12. Herman $P$, Krüger JA, Perini MV, Coelho FF, Lupinacci RM Laparoscopic hepatic posterior sectionectomy: a hand-assisted approach. Ann Surg Oncol. 2013;20(4):1266.

13. Koffron AJ, Kung RD, Auffenberg GB, Abecassis MM. Laparoscopic liver surgery for everyone: the hybrid method. Surgery 2007;142(4):463-8; discussion 468.e1-2. Erratum in: Surgery. 2008; 143(2):301

14. Koffron AJ, Auffenberg G, Kung R, Abecassis M. Evaluation of 300 minimally invasive liver resections at a single institution: less is more. Ann Surg. 2007;246(3):385-92; discussion 392-4.

15. Nanashima A, Sumida $Y$, Oikawa M, Nonaka T, Abo T, Takeshita $\mathrm{H}$, et al. Usefulness and limitation of laparoscopic assisted hepatic resections: a preliminary report. Hepatogastroenterology. 2009;56(90):447-51

16. Dindo D, Demartines N, Clavien PA. Classification of surgical complications: a new proposal with evaluation in a cohort of 6336 patients and results of a survey. Ann Surg. 2004;240(2):205-13. 
17. Herman P, Perini MV, Coelho F, Saad W, D'Albuquerque LA. HalfPringle maneuver: a useful tool in laparoscopic liver resection. J Laparoendosc Adv Surg Tech A. 2010;20(1):35-7.

18. Reich H, McGlynn F, DeCaprio J, Budin R. Laparoscopic excision of benign liver lesions. Obstet Gynecol. 1991;78(5 Pt 2):956-8.

19. Oida T, Mimatsu K, Kano H, Kawasaki A, Kuboi Y, Fukino N, et al. Minimal incision based on measurement of the to-be-resected specimen in laparoscopic hepatectomy. Hepatogastroenterology. 2012:59(120):2598-601.

20. Hüscher CG, Lirici MM, Chiodini S, Recher A. Current position of advanced laparoscopic surgery of the liver. J R Coll Surg Edinb. 1997;42(4):219-25.

21. Nitta H, Sasaki A, Fujita T, Itabashi H, Hoshikawa K, Takahara T, et al. Laparoscopy-assisted major liver resections employing a hanging technique: the original procedure. Ann Surg. 2010;251(3):450-3.

22. Soyama A, Takatsuki M, Adachi T, Kitasato A, Torashima $Y$, Natsuda K, et al. A hybrid method of laparoscopic-assisted open liver resection through a short upper midline laparotomy can be applied for all types of hepatectomies. Surg Endosc. 2014;28(1):20311.

23. Dagher I, O'Rourke N, Geller DA, Cherqui D, Belli G, Gamblin TC, et al. Laparoscopic major hepatectomy: an evolution in standard of care. Ann Surg. 2009;250(5):856-60.

24. Nitta H, Sasaki A, Otsuka Y, Tsuchiya M, Kaneko H, Wakabayashi G. Impact of hybrid techniques on laparoscopic major hepatectomies. J Hepatobiliary Pancreat Sci. 2013;20(2):111-3.

25. Zhang $X$, Yang J, Yan L, Li B, Wen T, Xu M, et al. Comparison of laparoscopy-assisted and open donor right hepatectomy: a prospective case-matched study from China. J Gastrointest Surg. 2014;18(4):744-50.
26. Imura S, Shimada M, Utsunomiya $T$, Morine $Y$, Wakabayashi $G$, Kaneko H. Current status of laparoscopic liver surgery in Japan: results of a multicenter Japanese experience. Surg Today. 2014;44(7):1214-9.

27. Ferrero A, Langella S, Giuliante F, Viganò L, Vellone M, Zimmitti G, et al. Intraoperative liver ultrasound still affects surgical strategy for patients with colorectal metastases in the modern era. World J Surg. 2013;37(11):2655-63.

28. Cho A, Asano T, Yamamoto $H$, Nagata M, Takiguchi N, Kainuma $O$, et al. Laparoscopy-assisted hepatic lobectomy using hilar Glissonean pedicle transection. Surg Endosc. 2007;21(8):1466-8.

29. Tang CN, Li MK. Laparoscopic-assisted liver resection. J Hepatobiliary Pancreat Surg. 2002;9(1):105-10.

30. Itano O, Chiba N, Maeda S, Matsui H, Oshima G, Wada T, et al. Laparoscopic-assisted limited liver resection: technique, indications and results. J Hepatobiliary Pancreat Surg. 2009;16(6):711-9.

31. Johnson LB, Graham JA, Weiner DA, Smirniotopoulos J. How does laparoscopic-assisted hepatic resection compare with the conventional open surgical approach? J Am Coll Surg. 2012:214(4):717-23; discussion 723-5.

Received at: 06/10/2014

Accepted for publication: 03/01/2015

Conflict of interest: none.

Source of funding: none.

Mailing address:

Fabricio Ferreira Coelho

E-mail: ff_coelho@hotmail.com or fabricio.coelho@hc.fm.usp.br 